\title{
Gender, Culture and Entrepreneurship in Kenya
}

\author{
Esther N. Mungai \\ Center for Entrepreneurship Innovation and Technology Transfer (CEITT) \\ Kenya polytechnic University College, Nairobi, Kenya \\ E-mail: ethuku@hotmail.com \\ Madara Ogot \\ School of Business and Economics, Maseno University, Maseno, Kenya \\ E-mail: madaraogot@maseno.ac.ke
}

Received: July 18, 2011

Accepted: March 12, 2012 Published: May 1, 2012

doi:10.5539/ibr.v5n5p175

URL: http://dx.doi.org/10.5539/ibr.v5n5p175

\begin{abstract}
This study looked into how different cultural factors affect gender involvement in entrepreneurship in a multi-ethnic country, Kenya. A majority of previous similar studies have been done in Western, developed societies where national cultures have evolved and have dominated the literature on the 'cultural perspective' on gender and entrepreneurship. In the majority of sub-Saharan countries, ethnic cultures play a more dominant role in moulding the values and perceptions of its citizens than national cultures. The differential rate of gender involvement was compared among four Kenyan ethnic groups namely Luo, Kikuyu, Kalenjin and Kamba. A significant outcome of the study, is that there were neither significant gender differences on community perception of entrepreneurship nor the extent on the presence (or absence) of personality traits associated with entrepreneurship. From the study, it appears that for the communities studied, ethnic cultural influences play a larger role in women's propensities towards entrepreneurship and their view of their community perception towards the same, than does gender. This is pronounced even when men and women from the same communities are compared along the same dimensions.
\end{abstract}

Keywords: Gender, Entrepreneurship, Ethnicity

\section{Introduction}

Entrepreneurship in Africa has been perceived differently among scholars and researchers. One view is that there is lack of entrepreneurial talent in Africa which has resulted in fewer establishments and management of manufacturing industries for productive activities (Morch, 1995). The alternative view is that entrepreneurial talent is indeed available but that economic environment has not been conducive to allow this talent to develop (Adjebeng-Asen, 1989). This study takes on another view, that Africa entrepreneurship is alive and well but the various local cultures especially with regard to Gender, tacked on to a characteristic multi-ethnic African nation may hinder the development of entrepreneurial culture.

Gender role is a cultural orientation or attribute conditioned by a traditional social system in which men are expected to behave as men (Masculine) and women are expected to think and behave as women (Feminine). A consistent empirical result emerging in the literature on female entrepreneurship is that gender matters. In particular, women exhibit a consistently lower likelihood of becoming an entrepreneur than their male counterparts (Van Gelderen, 1999; Diochon et al., 2002; Reynolds et al., 2004; Wagner, 2005). With African nations being dominantly patriarchal, the extent to which women are able to freely participate in entrepreneurship activities will largely be determined by the existing cultural atmosphere.

Considering the various cultural and structural challenges and obstacles facing women, someone may quickly conclude that women are usually discouraged from venturing into enterprise development. First, early socialisation practices emphasise the primary role of women as mothers and wives, influencing girls' total expectations for future participation in the labour force and the choice of career paths. Second, an African culture is mainly seen as a barrier to development because it perpetuates culturally sanctioned biases against women and provides excuses for men (Kiriti, et al., 2003b). This has resulted in lower participation of women in business activities. 
The current study limits its scope to cultural factors and how these cultural factors differently affect gender involvement in entrepreneurship. Culture in this sense is defined as a set of shared values, beliefs and expected behaviours (Hofstede, 1980). For the purpose of this study, the concept of ethnicity and gender will be explored as proxies of culture, wherein different ethnic groupings are assumed to practice distinct cultures and varying gender roles. One striking feature in the literature is the entrepreneurial activity variations among cultures and gender. Of interest in this study is whether entrepreneurial activities vary among gender across the ethnic cultures, and whether the cross cultural ethnic differences are apparent between genders within the separate cultures among Kenya's ethnic groups. The differential rate of gender involvement will be compared among four Kenyan ethnic groups namely the Luo, Kikuyu, Kalenjin and Kamba. An earlier study indicated significant differences in the manifestation of entrepreneurial traits among the mentioned ethnic groups (Mungai \& Ogot, 2010). However, gender disparities were not considered, which is the focus of this study.

\section{Motivation and Literature Review}

Traditionally, cultural ideas on gender often mean that men are seen and see themselves as more instrumental and committed to business activities and career than women (Alvesson, 2002). Thus, men were and still are privileged in terms of social position, career, income and authority. Most cultures, particularly in Africa are of masculine nature, with masculine notions, stereotypes, values, beliefs and assumptions. The argument that cultures should be gender-neutral has been advanced severally. One of the main concepts emphasized in line with this argument is "creating equal opportunities," which involves the elimination of structural and cultural barriers and biases that inhibits women participation in business activities and advancement at workplace (Podony \& Baron, 1997; Burt, 1992; Ibarra, 1992; Morrison, et al., 1987).

Existing research in this field have only covered "gender equality" at the work place. They failed to conduct extensive and in-depth investigation on societies with a pattern of shared values, beliefs and traits which are ideally associated with culture. Further, much of the evidence on gender-related entrepreneurial activity comes from studies based in United States and European countries; the generalizability of these findings in an African setting is questionable. This is considered an important research gap in the current study. To fill this gap, the study suggests a cultural dimension to gender differences within and across ethnic groups, and proposes to empirically test the impacts of such differences on entrepreneurial behavior as perceived by members of those ethnic communities within an African context, Kenya.

In addition, the study seeks to further our understanding of the connections between gender, ethnicity and entrepreneurship in a number of ways. First, it disentangles the effects of ethnic cultures on either gender from the manifestation of entrepreneurial traits (also culturally determined) as perceived by members of those ethnic communities. Second, it delves deeper into the concept of female ethnicity and explores if there exists differences in gender involvement in entrepreneurship activities among the different ethnicities. Analysis of the two variables will be based on perceptions by members of those particular communities. This approach is necessary to enable analysis that will distinguish the cultural constraints that women face in entrepreneurship in Kenya.

Few studies have looked at cultural impact on gender involvement in entrepreneurship. Themes within studies that have "gender as a variable" include money (Alsos et al., 2006; Orser et al., 2006), management issues such as attitudes towards growth (Wiklund et al., 2003), expectancy of entrepreneurial performance (Gatewood et al., 2002), networks (Greve \& Salaff, 2003), the issue of homemakers (Singh \& Lucas, 2005), participation of women in the labour force (Noorderhaven et al., 2004); childcare (Williams, 2004), amongst others.

Much less attention has been paid to the gender characteristics of the members of the different ethnic communities who exist within cultural settings that clearly define specific roles that ought to be played by each gender and, in particular, the extent to which the involvement of women in entrepreneurial activities is either acceptable or unacceptable. This is of particular importance given that over $80 \%$ of the Kenyan population, as in the majority of sub-Saharan African countries, lives in the rural areas that by and large can be classified as ethnic enclaves. As a result the majority of citizens' attitudes, tendencies and behaviour are influenced more by culture within their communities, than by a national culture as would be the case in American or European countries where national cultures dominate.

It therefore raises some interesting research questions: (1) what role does ethnic culture plays in influencing gender involvement in entrepreneurship? (2) To what extent does ethnic culture influence gender differences in personality traits associated with entrepreneurship? These are the questions that this study seeks to answer.

\subsection{Relationship between Gender, Ethnicity and Entreprenuership}

Results from the GEM 2007 study indicate that over the previous decade, women had a lower average score on the total entrepreneurial activity (TEA) index as compared to men, world over. (Allen, Elam, Langowitz \& Dean, 2007). Earlier studies indicate that women are more vulnerable because tradition usually gives them less decision-making 
power over assets than men, while at the same time their opportunities to engage in remunerated activities, and therefore to acquire their own assets, are more limited (World Bank, 1995, 1996; Blackden \& Bhanu 1998; Greer \& Thorbecke, 1986a, 1986b; Collier \& Lal, 1980; Republic of Kenya, 1991, 1998). In a different study, Kiriti, et al. (2003a) found that in patriarchal societies, such as Kenya, customary conventions play a major role in determining the socio-economic status and inolvement for women in entreprenueral activities.

While Africa continues to strongly uphold patriarchal values, this impacts heavily on women's ability to build businesses in many contexts. Cultural/ethnic values can play a critical role in determining who gets into entrepreneurship and what functional role each plays in this activity. Holuquist and Sundin (1987) suggest that women and men operate in two separate worlds with quite different value systems. Evidence also shows that distinct ethnic groups assume their own behavioral expectations, with some communities emphasizing purely domestic chores for women (passivity in entrepreneurial activities), and others financial independence for both genders. Still for others, the path to entrepreneurship is reflective of women's frustrations encountered at the domestic front.

Cultural pressures and expectations to maintain sexual piety, as well a 'sound moral reputation' are brought to bear on women. These pressures impinge significantly on the economic factors that women face (Lessinger, 1990). Such pressures constrain women's mobility, limit whom they talk to, and conduct business with, and structure their relationship to the market. For example, a study by Chitsike (2000) in Zimbabwe among the Shona, found that some women view making large amounts of money as a dirty pursuit, full of all kinds of evil ("she wants to make money like a prostitute"). Women are traditionally brought up to associate making money with immorality. Thus any entrepreneurial venture pioneered by a woman is frowned upon. There is therefore need to overcome cultural barriers that specifically face women who would otherwise want to engage in venture creation (ILO, 1997) especially in Africa.

\subsection{Psychological Traits and Entrepreneurial Orientation}

Undoubtedly, there exists a link between psychological traits and entrepreneurship (Lumpkin \& Dess, 1996). People with a certain set of psychological traits may have a tendency to exhibit a certain degree of entrepreneurship. Prior research studies have identified achievement need, tolerance for ambiguity, risk taking and locus of control as correlates of being or desiring to be an entrepreneur (Ahmed, 1985; Begley \& Boyd, 1987; Bonnett \& Furnham, 1991). The current study will limit itself to investigation of only two of these traits: risk taking and locus of control. The two traits are also considered as some of the less disputed traits in regard to entrepreneurial behavior. A summary discussion of the two traits is covered in the section that follows.

Risk taking refers to the willingness to commit significant resources to some uncertain opportunities (Miller, 1983; Limpkin \& Dess, 1996; Baker \& Sinkula, 2009). A high risk taking propensity is often attributed to entrepreneurs. Although some of the empirical findings are contradictory, the overall evidence is that entrepreneurs are risk takers. The topic of risk (i.e. chance of failure) has remained current in more recent academic literature on entrepreneurship. Kihlstrom and Laffont (1979) emphasize that individuals differ in 'risk aversion'. In their model, "more risk averse individuals become workers while the less risk averse become entrepreneurs." Uncertainty is particularly relevant for start-up entrepreneurs because they cannot know the full range of possible outcomes (Bhide, 1994).

Locus of control represents an individual's perceptions about the rewards and punishments in his/her life (Pervin \& John, 1980). While individuals with an internal locus of control believe that they are able to control life's events, individuals with an external locus of control believe that life's events are the result of external factors, such as chance, luck or fate. Rotter (1966) hypothesized that those with an internal locus of control would more likely strive for achievement compared with those with an external locus of control. Brockhaus and Horwitz (1986), suggested further that locus of control could distinguish entrepreneurs who are successful from those who are unsuccessful. Generally, it is believed that entrepreneurs prefer to take and hold unmistakable command instead of leaving things to external factors (Mitton, 1989). Empirical findings that internal locus of control is an entrepreneurial characteristic has been reported in the literature (see, for example, Koh et al. (1992) and Robinson et al. (1991)).

\section{Study Methodology and Results}

The study sought to answer the previously stated two research questions by posing the following four hypotheses:

H1: There is a significant difference in the relationship between ethnic culture and gender involvement in entrepreneurship.

$\mathrm{H} 2$ : There is a significant difference in the presence of personality traits associated with entrepreneurship across gender within the ethnic groups.

H3: There is a significant difference between men and women's perception of entrepreneurship of their ethnic communities. 
H4: There is a significant difference among women of different ethnic communities on their perception of entrepreneurship of their communities.

A structured questionnaire, adopted from Hofstede (1984), was developed to indirectly determine the level of two major personality traits associated with entrepreneurship (Risk taking and Locus of Control), as well as determine the participants perception of entrepreneurship. The selection of the items from Hofstede's tool was based on its applicability to an institutional setting, such as an ethnic community. The four Kenyan communities selected were the Kikuyu, Kamba, Luo and Kalenjin.

All questions were based on 5-point Likert scales facilitating ready quantification of the outcomes.

To measure the level of Risk Aversion, respondents were asked:

1. Would you take the risk of investing your money where the outcome is unknown? (R2)

2. Do you always need to know that it has been done before you are willing to try it? (R2, I)

3. Most people can be trusted. (R4)

4. In choosing an ideal job security of employment is of. (R1, I)

5. In your personal life, how important is personal steadiness and stability? (R1)

The codes in brackets at the end of each questions indicates the rating scale used as described in Table 1. An aggregate score of 1 indicates a low level of risk aversion, with a score of 5 being high.

To measure the level of Locus of Control respondents were asked:

1. One can easily run a successful enterprise. (R4)

2. When people have failed in life, it is often their own fault. (R4)

3. Do you often feel, 'That is just the way things are and there is nothing I can do about it.' (R2, I)

4. When things go right and are terrific for you, do you think, 'I was lucky'? (R2, I)

An aggregate score of 1 indicates a high locus of control, with a score of 5, low. Finally, to measure the perception of entrepreneurship within the communities respondents were asked:

1. How would you describe the general reaction of your community to entrepreneurial behaviour? (R5)

2. How are successful business people generally viewed by your community? (R6)

3. How do you perceive your community's orientation to entrepreneurship? (R7)

An aggregate score of 1 indicates a high positive perception of the community on entrepreneurship, with a score of 5 , a low perception.

A survey of 120 participants was carried out using a stratified sampling technique to ensure inclusion of equal male and female participants in all the four ethnic groups. Multi-stratification was done on the basis of gender and ethnicity. Thirty respondents were drawn from each ethnic stratum using simple random sampling, within which an equal number of male and female respondents were sought.

\subsection{General Results}

Table 2 provides the overall descriptive statistics and correlations between the three measures teased out from the questionnaires. Within the table, the scales are from 1 - 5, with 1 showing the highest level (presence) of the particular measure. Table 3 breaks down the descriptive statistics according to gender. Table 4, further stratifies the descriptive statistics according to Gender and Ethnicity.

\subsection{Test of Hypotheses}

\subsubsection{Hypothesis 1}

Hypothesis 1 posited that there is a significant difference in the presence of personality traits associated with entrepreneurship between men and women in Kenya. Responses were first compared between men and women from the total sample along the two dimensions of risk and locus of control. Z-tests were performed to test the hypotheses that There is a significant difference in the presence of personality traits associated with entrepreneurship between men and women in Kenya. Results from the z-tests are presented in Table 5 and 6. From the results, both hypotheses are rejected, showing that for the total sample, there is no significant difference between men and women.

Further investigations using t-tests were carried out to determine if there are any significant differences between men and women within their ethnic communities for the two personality traits. Due to unequal sample sizes and unequal variances, the Welch-Satterwaite Equations was used to calculate the degrees of freedom. Results from the t-tests are 
shown in Table 7. From the table and at $95 \%$ confidence, the difference between men and women within each ethnic group were not found to be significant. Globally or within ethnic communities, Hypothesis 1 is not supported.

\subsubsection{Hypothesis 2}

Hypothesis 2 posited that there is significant difference between women of different ethnic communities in the manifestation of entrepreneurship personality traits. Scheffe's F-tests were used to compare all pairs of ethnic communities along the two personality dimensions. Scheffe comparison test is considered to be conservative, and well suited to unequal sample sizes and variances. It is also relatively insensitive to departures from normality and homogeneity of variances (Des \& Davis, 1984). Results from the Scheffe tests are shown in Tables 8 and 9. At 95\% confidence level, along the risk dimension, the Kikuyu women were significantly different from women in all the other communities. Along the locus dimension, only the Kikuyu and Kamba showed any significant differences. Hypotheses 2 is therefore partially supported. Of significance is that cultural norms appear to play a larger role in the extent of the presence of the personality traits then gender.

\subsubsection{Hypothesis 3}

Hypothesis 3 posited that there is a significant difference between men and and women's perception of entrepreneurship of their ethnic communities. To test the hypotheses z-tests were performed on the global sample with results presented in Table 7. From the results, there is no significant difference at the $95 \%$ confidence level. Investigations were also performed to ascertain if there were significant differences on community perception of entrepreneurship between men and women within their own ethnic communities. Results from the t-tests are shown in Table 7. At 95\% confidence level, the difference between men and women within each ethnic community were found not to be significant. On a global view or within ethnic communities hypothesis 3 is not supported.

\subsubsection{Hypothesis 4}

Finally, Hypothesis 4 posited that there is significant difference between women of different ethnic communities in their perception of entrepreneurship in their communities. Results of Scheffe tests are shown in Table 11. At 95\% confidence level, there are significant difference between the Kikuyu and all other communities. Other comparisons were not significant. Hypothesis 4 is therefore partially supported. Again of significance is that cultural norms appear to play a larger role in the extent of the community perception of entrepreneurship then gender.

\section{Conclusions}

Significant studies have been done looking into the role of gender in promoting or hindering entrepreneurial activities. A majority of the studies have been done in Western, developed societies where national cultures have evolved and have dominated the literature on the 'cultural perspective' on gender and entrepreneurship. In the majority of sub-Saharan countries, ethnic cultures play a more dominant role in moulding the values and perceptions of its citizens than national cultures. This study sought to look at gender and ethnic cultural influences on perceptions of entrepreneurship among four ethnic communities in Kenya.

A significant outcome of the study, is that there were no significant gender differences on community perception of entrepreneurship nor the extent on the presence (or absence) of personality traits associated with entrepreneurship. However on both risk taking and community perception dimensions, there were significant differences between Kikuyu women and women from other communities. From the study, it appears, therefore that for the communities studied, ethnic cultural influences play a larger role in women's propensities towards entrepreneurship and their view of their community perception towards the same than does gender. This is pronounced even when men and women from the same communities are compared along the same dimensions.

Finally, this work represents a preliminary effort into this rich area of study. The study was limited in that only four ethnic communities were selected, with a small sample size within each community, and from each gender. Further, all respondents were drawn from Nairobi, thereby negating some of the ethnic enclave effects. In addition, only the two dominant traits: risk aversion and locus of control were investigated. Despite these limitations, however, this study suggests that for the participating ethnic groups (Kikuyu, Kamba, Kalenjin and Luo), cultural norms appear to almost equally hinder or promote perceptions on entrepreneurship for women and men. This differs from the study done in Zimbabwe where ethnic cultural influences created large gaps in entrepreneurship perceptions between men and women (Chanock, 1985).

\section{References}

Blumberg, R. L. (1989). Makingt he case for the genderv ariable: Women and the wealth and well-being of nations. In Technical Reports in Gender and Development. Washington DC: USAID-WID.

Boris, E., \& Prugl, E. (1996). Homeworkers in global perspective. London: Routledge. 
Boserup, E. (1970). Woman's role in economic development. London: Earthscan.

Carr, M., Chen, M., \& Jhabvala, R. (1996). Speaking out: Women's economic empowerment in South Asia. London: Intermediate Technology.

Carter, N. M., \& Kolvereid, L. (1998). Women starting new businesses: The experience in Norway and the U.S. In Women Entrepreneurs in small and medium enterprises. Paris: Organization for Economic Cooperation and Development.

Chanock, M. (1985). Law custom and social order; the colonial experience in Malawi and Zambia. Portsmouth: Heinemann.

Chen, M. A. (1989). A sectoral approach to promoting women's work: Lessons from India. World Development, 17(7), 1007-1016. http://dx.doi.org/10.1016/0305-750X(89)90164-2

Chitsike, C. (2000). Culture as a Barrier to Rural Women's Entrepreneurship: Experience from Zimbabwe. Gender and Development, 8(1), 71-77. http://dx.doi.org/10.1080/741923408

Cowling, M. (2000). Are entrepreneurs different across countries?. Applied Economics Letters 7(12), 785-89. http://dx.doi.org/10.1080/135048500444804

Dess, G., \& Davis, P. S. (1984). Porter's (1980) Generic strategies as determinants of strategic group membership and organization performance. The Academy of Management Journal, 27(3), 467-488. http://dx.doi.org/10.2307/256040

Downing, J. (1990). Gender and the growth and dynamics of microenterprises. Working paper no. 5, Gemini, Washington, DC.

Ehlers, T. B., \& Main, K. (1998). Women and the false promise of microenterprise. Gender and Society, 12(4), 424-440. http://dx.doi.org/10.1177/089124398012004004

Ferree, M. M. (1990). Beyond separate spheres: Feminism and family research. Journal of Marriage and the Family 52, 866-84. http://dx.doi.org/10.2307/353307

Heyer, A. (2006). The Gender of wealth: Markets and power in Central Kenya. Review of African political Economy, 33(107), 67-80. http://dx.doi.org/10.1080/03056240600671361

Holmquist, C., \& Sundin, E. (1987). The Growth of women entrepreneurship? Push or pull factors. Working Paper, Umea University.

Hornaday, J., \& Aboud, J. (1971). Characteristics of successful entrepreneurs. Personnel Psychology, 21(Summer), 141-53.

ILO. (1997). Second start your business impact evaluation report: Uganda, Zambia and Zimbabwe.

International Labor Organization (ILO). (1999). Gender issues in the world of work: Gender issues in micro-enterprised evelopment. Geneva: International Labor Organization.

Kantor, P. (2002). A sectoral approach to the study of gender constraints on economic opportunities in the informal sector in India. Gender and Society, 16(3), 285-302. http://dx.doi.org/10.1177/0891243202016003002

Koper, G. (1993). Women entrepreneurs and the granting of business credit. In S. Allen and C. Truman (Eds.), Women in business: Perspectives on women entrepreneurs. London: Routledge.

Levitsky, J. (1996). Support systems for MSEs in developing countries: A review. Vienna: UNIDO.

MacIsaac, N. (1996). Micro-enterprise support: A critical review. Ottawa: The Canadian Council for International Cooperation, Policy Team.

Mahot, P. (1998). Funding for women entrepreneurs: A real-though disputed-problem. In Women entrepreneurs in small and medium enterprises. Paris: Organization for Economic Cooperation and Development.

McClelland, D. G. (1961). The Achieving Society. New York: Van Nostrand Company Inc.

Nelson, M. K., \& Smith, J. (1998). Economic restructuring household strategies and gender: A case study of a rural community. Feminist Studies, 24, 79-114. http://dx.doi.org/10.2307/3178620

Nussbaum, M. (2000). Women and development: The capabilities approach. New York: Cambridge University Press.

Otero, M. (1989). Solidarity group programs: A working methodology for enhancing the economic activities of women in the informals ector. In M. Berger and M. Buvinic (Eds.), Women's ventures:A ssistance to the informal sector in Latin America. West Hartford CT: Kumarian Press. 
Papanek, H. (1990). To each less than she needs, from each more than she can do: Allocations, entitlements, and value. In I. Tinker (Ed.), Persistent inequalities. Oxford, UK: Oxford University Press.

Stichter, S. (1990). Women, employment and the family: Current debates. In S. Stichter and J. Parpart (Eds.), Women employment and the family in the international division of labour. Philadelphia:Temple University Press.

van Der Wees, C., \& Romijn, H. (1995). Entrepreneurship and small-and micro enterprised evelopment for women: A problematique in search of answers, a policy in search of programs. In L. Dignard and J. Havet (Eds.), Women in micro-and small-scale enterprise development. Boulder, CO: Westview.

Weidemann, C. J. (1995). Micro enterprise and gender in India: Issues and options. Gemini technical report no. 93. Washington, DC: Gemini.

World Bank. (1989). Women in development: Issues for economic and sector analysis. Washington, DC: Population and Human Resources Department, WPS 269, World.

Table 1. Rating scales used in the questionnaire

\begin{tabular}{ll}
\hline Code & Scale \\
\hline I & Scale is inverted in the numeric analyses \\
R1 & 1-Utmost importance; 2-Very Important; 3-Moderate importance; 4-Little importance; 5-Very little or no importance \\
R2 & 1-Always; 2-Usually; 3-Sometimes; 4-Seldom; 5-Never \\
R3 & 1-Very frequently; 2-Frequently; 3-Sometimes; 4-Seldom; 5-Never \\
R4 & 1-Strongly agree; 2-Agree; 3-Undecided; 4-Disagree; 5-Strongly disagree \\
R5 & 1-Extremely good; 2-Good; 3-Indifferent; 4-Hostile; 5-Extremely hostile \\
R6 & 1-Very highly; 2-Highly; 3-Indifferent; 4-Fairly; 5-Very lowly \\
R7 & 1-Very good; 2-Good; 3-Fair; 4-Bad; 5-Very bad \\
\hline
\end{tabular}

Table 2. Overall descriptive statistics and correlations

\begin{tabular}{lllll}
\hline Variables & Mean & SD & Risk & Locus \\
\hline Risk & 3.00 & 0.72 & & \\
Locus & 2.70 & 0.64 & 0.22 & \\
Community & 2.47 & 0.73 & 0.37 & 0.22 \\
\hline
\end{tabular}

Table 3. Descriptive statistics by gender

\begin{tabular}{llll}
\hline & Risk & Locus & Commun. \\
\hline Male & 3.02 & 2.70 & 2.54 \\
Female & 2.97 & 2.71 & 2.39 \\
\hline
\end{tabular}

Table 4. Descriptive statistics by gender and ethnicity

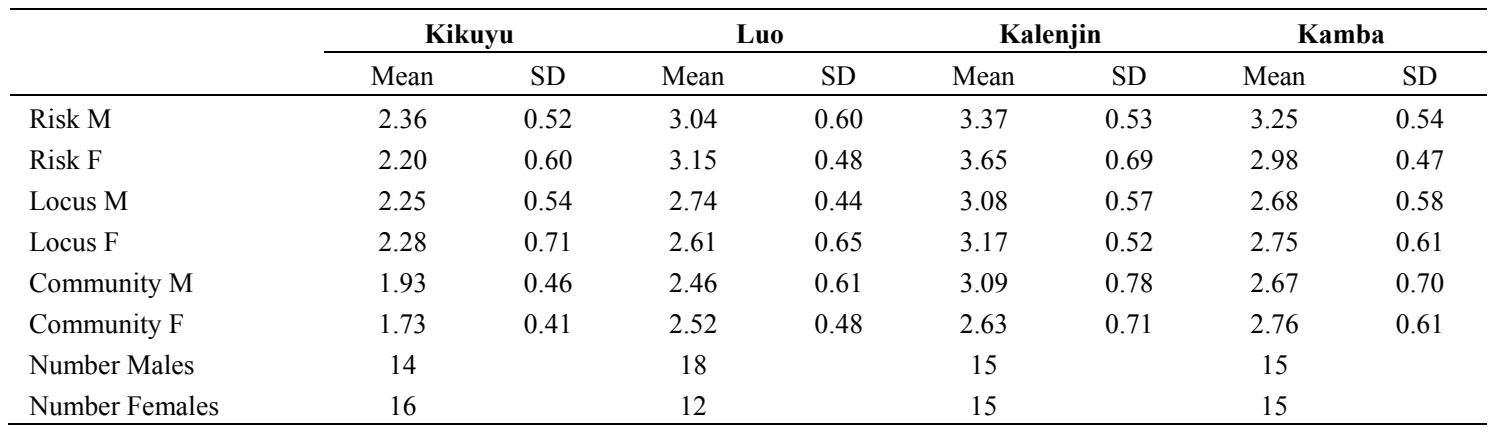


Table 5. z-tests of the hypothesis: There is a significant difference in the presence of risk taking personality trait associated with entrepreneurship between men and women in Kenya

\begin{tabular}{lll}
\hline & Men & Women \\
\hline Mean & 3.02 & 2.97 \\
Known Variance & 0.43 & 0.6 \\
Observations & 62 & 58 \\
Hypothesized Mean & 0 & \\
$\mathrm{Z}$ & 0.32 & \\
$\mathrm{P}(\mathrm{Z}<=\mathrm{z})$ two-tail & 0.75 & \\
$\mathrm{Z}$ Critical two-tail & 1.96 & \\
\hline
\end{tabular}

Table 6. z-tests of the hypothesis: There is a significant difference in the presence of locus of control personality trait associated with entrepreneurship between men and women in Kenya

\begin{tabular}{lll}
\hline & Men & Women \\
\hline Mean & 2.7 & 2.71 \\
Known Variance & 0.35 & 0.48 \\
Observations & 62 & 58 \\
Hypothesized Mean & 0 & \\
$\mathrm{Z}$ & -0.12 & \\
$\mathrm{P}(\mathrm{Z}<=\mathrm{z})$ two-tail & 0.91 & \\
$\mathrm{Z}$ Critical two-tail & 1.96 & \\
\hline
\end{tabular}

Table 7. t-test values and p-values (in brackets) from two-tailed, t-tests between men and women within each of the four ethnic group along each of the two personality dimensions and on community perceptions on entrepreneurship

\begin{tabular}{lllll}
\hline & Kikuyu & Luo & Kalenjin & Kamba \\
\hline Risk & 0.756 & 0.603 & 1.255 & 1.442 \\
& $(0.456)$ & $(0.527)$ & $(0.221)$ & $(0.161)$ \\
Locus & 0.137 & 0.550 & 0.449 & 0.309 \\
& $(0.892)$ & $(0.587)$ & $(0.657)$ & $(0.760)$ \\
Community & 1.255 & 0.256 & 1.731 & 0.370 \\
& $(0.221)$ & $(0.800)$ & $(0.095)$ & $(0.714)$ \\
\hline
\end{tabular}

Table 8. Scheffe F-tests of the hypothesis that there is a significant difference in the presence of risk personality trait associated with entrepreneurship between women from different ethnic groups in Kenya (P-values given in brackets)

\begin{tabular}{llll}
\hline & Luo & Kalenjin & Kamba \\
\hline Kikuyu & 6.18 & 16.44 & 4.78 \\
& $(0.0011)$ & $(0.0000)$ & $(0.0050)$ \\
Luo & & 1.72 & 0.18 \\
& & $(0.1740)$ & $(0.9105)$ \\
Kalenjin & & & 3.38 \\
& & & $(0.0246)$ \\
\hline
\end{tabular}

Table 9. Scheffe F-tests of the hypothesis that there is a significant difference in the presence of locus personality trait associated with entrepreneurship between women from different ethnic groups in Kenya (P-values given in brackets)

\begin{tabular}{llll}
\hline & Luo & Kalenjin & Kamba \\
\hline Kikuyu & 0.78 & 5.37 & 1.45 \\
& $(0.5116)$ & $(.0026)$ & $(0.2383)$ \\
Luo & & 1.64 & 0.06 \\
& & $(0.1902)$ & $(0.9797)$ \\
Kalenjin & & & 1.2 \\
& & & $(0.3181)$ \\
\hline
\end{tabular}


Table 10. z-tests of null hypothesis: There is no significant difference between men and women's perception of entrepreneurship of their ethnic communities

\begin{tabular}{lll}
\hline & Men & Women \\
\hline Mean & 2.54 & 2.39 \\
Known Variance & 0.57 & 0.48 \\
Observations & 62 & 58 \\
Hypothesized Mean & 0 & \\
$\mathrm{Z}$ & 1.15 & \\
$\mathrm{P}(\mathrm{Z}<=\mathrm{z})$ two-tail & 0.25 & \\
$\mathrm{Z}$ Critical two-tail & 1.96 & \\
\hline
\end{tabular}

Table 11. Scheffe F-tests of the hypothesis that there is a significant difference in the perception between women from different ethnic groups in Kenya on their communities view of entrepreneurship (P-values given in brackets)

\begin{tabular}{llll}
\hline & Luo & Kalenjin & Kamba \\
\hline Kikuyu & 3.92 & 7.05 & 8.45 \\
& $(0.0132)$ & $(0.0004)$ & $(0.0001)$ \\
Luo & & 0.26 & 0.55 \\
& & $(0.8530)$ & $(0.6472)$ \\
Kalenjin & & & 0.06 \\
& & & $(0.9799)$ \\
\hline
\end{tabular}

